IFN Working Paper No. 737, 2008

\title{
Protection of Property Rights and Growth as Political Equilibria
}

Andrea Asoni 


\title{
Protection of Property Rights and Growth as Political
}

\author{
Equilibria
}

\author{
Andrea Asoni* $^{*}$ \\ Department of Economics \\ University of Chicago
}

March 5, 2007

\begin{abstract}
This paper presents a survey of the literature on property rights and economic growth. It discusses different theoretical mechanisms that relate property rights to economic development. Lack of protection of property rights can result in slow economic growth through different channels: expropriation of private wealth, corruption of civil servants, excessive taxation and barriers to adoption of new technologies. The origins of property rights are also considered. Different theories are illustrated but more attention is paid to the "social conflict view" and its strengths and limitations. The second part of the paper illustrates relevant empirical works on property rights and growth.
\end{abstract}

Key words: Institutions; Economic development; Property rights; Social conflict view.

JEL classification: O11; O12; O43; P14; P16.

\footnotetext{
* This paper was written while the author was a visiting scholar at the Research Institute of Industrial Economics in Stockholm, Sweden (www.ifn.se). I am grateful for useful comments and suggestions on an earlier draft of this paper from Robin Douhan, Magnus Henrekson, Tino Sanandaji, Daniel Waldenström and two anonymous referees. Please send any comments or suggestions to asoni@uchicago.edu.
} 


\section{Introduction}

Economic growth is one of the main concerns of economists. As famously expressed by Lucas (1988), once one starts to consider the potentials of a better understanding of economic growth for human welfare, "it’s hard to think about anything else”.

What defines economic growth is the sustained increase in long-run per capita income. Such an increase can be achieved through the accumulation of factors of production ${ }^{1}$, or through a greater efficiency in the use of such factors. More efficiency is often the result of improvements in technology, especially regarding long-run sustained improvement. This technology is, in turn, generally embodied in physical capital (machines) or in human capital (increased skills of workers). Economists initially focused on savings and capital accumulation (Solow 1956), later turning to technological change as a profit maximizing investment (Romer 1990), learning on the job (Stokey 1988) etc. Economists have also increasingly taken into account the role of institutions for determining both capital accumulation and technological improvement. The focus in the literature has thus shifted away from the mechanics of growth toward its root causes. It seems to have been easy to dwell on explaining how, for example, the accumulation of human capital leads to increased economic output, thus ignoring the more important question of why that accumulation came to be in the first place. As expressed by North and Thomas (1973), "innovation, economies of scale, education, capital accumulation, etc [...] are not causes of growth; they are growth" (emphasis in the original).

The mechanisms behind economic growth must be sought in the incentives that individuals face to accumulate capital, work harder, get an education and organize resources in a more efficient way. Analyzing the potential environmental, cultural and political factors that determine these incentives is of equal importance. In this sense, there are (at least) three levels to the question of growth: How and to what extent factors of production and technology increase production, how institutions form the incentives to

\footnotetext{
${ }^{1}$ Traditionally land, labor, and physical capital. But, in fact, anything that contributes to value creation can be included, such as human capital, entrepreneurial effort, social networks and organizational capital.
} 
accumulate resources and technology, and finally, what factors determine the institutions themselves. This paper will mainly focus on the third of these issues.

Researchers have pointed out three factors that enable economic growth, and that have been put forward to explain the spread we observe in global economic standards: Geography, Trade and Institutions. Geography is a key determinant of natural resource endowment, such as quality of soil, disease burden, communication and transportation costs and the potential for diffusion of technology from more advanced areas (Diamond 1997, Sachs 2001).

Other researchers have put an emphasis on international trade and the beneficial exchange of goods and knowledge. Trade enables specialization according to comparative advantage, improves the worldwide allocation of resources, gives rise to economies of scale and differentiation through larger markets and reduced concentration in national markets. Sachs and Warner (1995) and Dollar and Kraay (2004) suggest trade and regional integration to be the main determinants of growth.

The third strand of research focuses on institutions, in particular on the protection of property rights, as the main determinants of growth. The main idea is that secure property rights create a sufficient incentive for individuals to invest in capital and in new and more efficient modes of organization of existing resources. A well-designed system of property rights aligns individual and social benefits from such productive activities.

All three factors certainly play a role in enhancing or hampering the process of economic growth and explain part of the differences in income levels among countries. However, there is increasing evidence suggesting that the main factor influencing economic growth is economic institutions. Acemoglu et al. (2001) effectively criticize the geographical hypothesis and jointly test institutions and geography. They conclude that the role of geography is mainly through its effects on political and economic institutions. Using a similar approach, Rodrik et al (2004) test institutions, geography and trade, and reach the same conclusion regarding the importance of institutions. The thesis put forward by 
North (1991) and North and Thomas (1973) is becoming the most widely accepted among economists and it also provides the focus of this paper. Hence, I will examine in more depth those institutions that protect property rights, limit the arbitrariness of political power and reward the efforts of the individuals. Or, in other words, those institutions that are considered to be the root cause of long-run economic growth.

The next section gives a quick overview of the rest of the paper while illustrating the main issues and terminology. Section 3 presents, discusses and criticizes the theoretical results of the literature. Section 4 presents some empirical evidence and discusses the limits of such evidence, describing how economists have overcome the statistical problems. Section 5 suggests some novel approaches to the issue. Section 6 concludes and summarizes the main theses of the paper.

\section{Property Rights in the Economics Literature}

Property rights are important for growth because they allow individuals to appropriate the returns of their efforts, encourage investments in capital, accumulation of knowledge and efficient organization of economic resources. "Protection of property rights" includes written laws and/or social customs and norms that describe how property can legally be acquired. It also entails the administrative and political bodies that enforce and protect such rights and shield the individuals from becoming dispossessed. Before Western countries developed a system of modern property rights, rulers could, for example, modify ownership rights through the exercise of unrestrained force or the control of judicial power. Other threats were raiders, bandits, and the lack of detailed deeds that increased the risk of conflict over boundaries. This reduced or even destroyed the incentives for individuals to invest in their land, or in other resources. In this regard, Acemoglu (e.g. Acemoglu et al. 2004) refers to a cluster of institutions that guarantee the property rights for a broad section of the population calling them "institutions of property rights”. An independent judiciary, constraints on the power of the executive and the role given to the Parliament on taxation are all measure for protecting private ownership from public or private predatory behavior. 
The literature describes various ways of infringing and threatening property rights. They all imply a distortion in the optimal choices of the agents, albeit in different ways. Economic historians and political scientists like North and Weingast (1989) and Olson (1982) considered the problem of excessive power held by the ruler of the society. With little or no checks on the ruler and his ability to exercise brute force and manipulate judicial courts, there was no security for individual rights and thus, less incentive to invest and create wealth. Examples usually considered by historians are the unrestrained, absolutist kings and princes of Europe before the English Civil War and the Glorious Revolution in 1688. These two events established the foundations of modern restrained governments and civil rights. Before the English Parliament was given the power over taxation, agents always faced the risk of expropriation by rulers who were always in need of money to finance their wars and court luxuries.

Another way of limiting property rights is through the lack of enforcement of written laws. If the case considered above refers to the lack of written or customary norms that limit the exercise of power, this second case refers to the lack of enforcement of such rules due to a corrupt bureaucracy or inefficient judicial power. There is a vast literature (e.g., Mauro 1995 and Johnson et al. 2002) on corruption and growth. This includes the negative effects of arbitrary powers of bureaucracy in terms of delayed or limited investment, misallocation of talent and information costs imposed on firms. Property rights are not fully protected if an agent must pay bribes to open shops, create factories or use his assets the way he prefers.

A third limitation on the capability to enjoy the returns of efforts is given by excessive taxation. An expropriative level of taxation also strongly discourages investments due to lower private returns. The probability of losing all your wealth through expropriation or a certainty of losing large parts of it through taxation have similar effects on the return to investments, with differences in the risk profile. Works by Alesina and Rodrik (1994) and Persson and Tabellini (1994), elaborate on this idea and the fact that the poor prefer more redistribution and hence, higher taxes. They argue that higher inequality leads to a lower 
growth rate; since societies with higher initial inequality and a poorer median voter will choose a higher level of taxation. This, in turn, reduces the incentive to invest and thus, impairs long-run economic growth.

A fourth possibility is discussed in Acemoglu (2005a); oligarchic societies where power is controlled by a minority of wealthy entrepreneurs may create barriers to entry of new entrepreneurs with better technologies. This limits the possibility of the new entrepreneurs to produce and sell their products on the market. The oligarchy is effectively limiting the property rights of new entrepreneurs through high barriers to entry.

If secure property rights are one of the core requirements for economic growth and if they play such an important role in the enhancement of human well-being, why do they not always come into existence? Why are they just a recent invention in the Western world and often completely lacking in the third world? History teaches us that property rights and the political institutions that guarantee their protection are a modern discovery and a fragile form of human collective organization. Past centuries were largely characterized by the rule of one individual over all others in the community and the almost absolute right of such autocrats, dictators or emperors, not only over people's belongings but also over their lives. The puzzling difficulty of imposing and sustaining wealth increasing institutions will be the other focus of this paper.

We need a theory of the rise, persistence and consequences of economic and political institutions. Perhaps States lacked the technology (broadly defined, either technical capabilities or suitable ideologies) to restrain themselves. Perhaps the ruler's timehorizon was too short; it has been argued (Olson, 1993) that the longer the life span of the ruler, the higher the incentive to protect property rights, favor investment and increase future tax revenues. Acemoglu et al. (2004) refer to three distinct theories about the rise of different institutions. The efficient institution theory sees them as the most efficient arrangement or contract between different individuals, given the technology and factor endowments. This idea is quite common among economists who tend to view most 
results as equilibria and as the outcome of some optimization problem. North and Thomas (1973), for example, argue that feudal institutions were efficient in the context of medieval Europe.

The second possibility is given by ideology. Different people have different ideas about what is good for the community and try to shape their common rules and institutions according to shared views about the world (another possibility is that institutions are shaped according to the ideology of the dominant group). The crucial aspect of this is the collective good nature of ideas. Individuals internalize the costs and benefits of gathering information and investing in cognitive costs for private decisions. However, they will only gain a miniscule fraction of the benefits of holding "good" and well informed political ideas, but bear all the costs. Communism is an inefficient way of organizing a society, but each communist college student only faces a fraction of the social costs of imposing communism. If the average living standards of western communists decreased with the difference in average income between capitalist and communist nations, we should expect to see fewer western communists.

The third explanation is called the "social conflict view". Different institutions have different distributional implications. The idea is that individuals do not care about the overall efficiency of political institutions, but about the distribution of resources under different arrangements. Institutions are developed in the political market by competing special interests. They take current institutions as given, i.e. "rules of the game" that cannot be changed by any single agent and over which different actors fight collectively. In the long run institutions are endogenous, a result of the struggle among the different groups, thus mirroring the distribution of power among competing interests and social classes.

This paper will focus on the "social conflict view" and will try to understand the benefits and the shortcomings of this approach. The social conflict view is indeed a powerful theory to understand the rise and development of different institutions. For this reason and due to its implications in understanding historical episodes, the theory is popular 
among social scientists. Convincing evidence on the importance of institutions in explaining economic growth and on their origins as arrangements between different political constituencies has been obtained. Still, our understanding of the problem is by no means complete. As I will argue later, we are still left with important questions like the reasons why some institutions are chosen instead of others. This cannot be satisfactorily explained by the social conflict view, and seems to require different approaches. In particular, the importance of those common values, beliefs and behaviors (in one word, culture) of people in explaining the rise, performance and persistence of political institutions remains to be understood.

\section{Theories on Property Rights}

The idea that property rights are crucial for development is clearly not novel. Major political philosophers in the $17^{\text {th }}$ and $18^{\text {th }}$ centuries such as Locke and Hume put much emphasis on the beneficial effects of private ownership. Locke considered private ownership, together with life and liberty, as one of the most important individual rights that should not be violated in any way by the intervention of the government. The importance of property rights protection for economic growth was also strongly emphasized by Adam Smith (1776). This idea has now become mainstream economics with the leading works of Acemoglu and many other economists who try to assess the relevance of Smith's and North and Thomas's (1973) intuitions.

The common understanding is that secure property rights create incentives for people to invest and produce more efficiently. The return from such activities is guaranteed not to suffer from predation. The first task of economists is to give a definition of property rights or, more accurately, of the protection of property rights. As reported in Cole and Grossman (2002) “As A. Allan Schimd (1999, 233) maintains, ‘[p]roperty is a social fact or it is no fact at all'”. The safeguard of property rights implies the existence of shared social norms recognizing individual property over and above common property, but this is not sufficient, however. The existence of administrative and political bodies that effectively implement and protect property is also required. As we will see later, not only 
the lack of such bodies but also the inefficiency of existing ones can be seen as an infringement of property rights.

Before proceeding to the description and critique of the current theoretical literature, a common misunderstanding should be noted. Protection of property rights is not equivalent to democracy. Historically, protection of property rights came before democracy (Baumol 2002). Nowadays, it is very hard to imagine a democracy that does not guarantee private ownership and a great deal of property rights protection. Nevertheless, the notion that liberal democracy is a political device for reinforcing individual rights to property is common, and most likely the result of an old debate that goes back to the nineteenth century. As described by Przeworski and Limongi (1993) "Karl Marx expressed the same conviction that private property and universal suffrage are incompatible [...]. According to his analysis, democracy inevitably 'unchains the class struggle': the poor use democracy to expropriate the riches; the rich are threatened and subvert democracy typically by 'abdicating' political power to the permanently organized armed forces. As a result, either capitalism or democracy crumbles”. The conclusion is flawed due to a misunderstanding of the opportunities offered to the poor by a democratic regime and a well-functioning system of property rights: they do not need to expropriate the rich, they can become rich themselves!

Not all scholars shared this view. North first becomes explicit about the institutions that would guarantee such protection in Institutions, institutional change and economic performance (1990), where he also identifies these institutions as democratic. North and Weingast (1989) make a similar point, writing that the rule of law and Parliamentary supremacy were just a commitment device that would constrain the king from abusing his fiscal power. Olson (1993) notices a correspondence between democracy and institutions that guarantees property rights: "The conditions that are needed to have the individual rights needed for maximum economic development are exactly the same conditions that are needed to have a lasting democracy” (emphasis in the original). 
In my opinion, the previous misunderstanding is due to the fact that the term democracy is generally used to label political regimes that extend voting rights to large segments of the population. This definition only captures part of the complex democratic phenomenon. Historically, democracy went through two phases. The first phase, which may be called "Liberal Democratization”, is the one to which North and Weingast (1989) refer. Institutions that credibly restrain the government from interfering with inalienable personal rights such as property, freedom and life constitute the first step toward modern democracies. This is the moment in which classical liberal practices were created, along with all those norms and administrative and political bodies that helped preserve and reinforce those rights. The second phase, which may be called "Mass Democratization", occurred later in history and is characterized by the extension of franchise to all or most of the people in a country. Usually, Mass Democracy was built on Liberal Democracy and it preserved the most important features of the former such as division of powers, protection of rights and the independence of judicial power.

Today, democracy represents the results of these two different movements and contains features from both. Through constitutional provisions, it preserves social norms and independent judicial power, all those liberal freedoms we are used to think about. Moreover, it is characterized by universal voting rights and majority rule as just as in Mass Democracies. In this sense, it is impossible to think that universal suffrage would necessarily destroy democracy. The extension of the franchise usually happened inside the framework of liberal democracies and despite all social tensions, the conflict between the poor and the rich could be coped with through the liberal institutions created long before. As we will see later, this is the case when the order in which different institutions were introduced (first individual rights and second majority rule) is of importance.

Modern economic research often generically talks about "good institutions", considering as such protection of property rights or constraint on the government, with little attention paid to the political regime. The term democracy usually refers to what is here called mass democracy. With these qualifications in mind, we can now more precisely discuss economic theories about property rights. 


\subsection{From Private Ownership to Economic Growth}

How can the protection of property rights be beneficial for growth? Ownership safeguard is a general principle that can have different practical applications. Economists have proposed models covering many possibilities. Ownership can be limited through expropriation activities by the government, excessive taxation, entry barriers impeding new entrepreneurs or technologies and inefficient or corrupt practices by civil servants. The negative effects of a lack of protection of property rights that first emerge are lower investments in physical and human capital. Limited property rights also result in less research and development and hence, less production of new technologies. Other problems are given by a distorted allocation of resources, both human and financial. This section will describe these different aspects, while considering the various ways in which property rights can be limited in order to classify the literature.

\section{Expropriation of Private Wealth}

Economic historians were the first to consider the role of institutions (North and Thomas 1973 or North and Weingast 1989). They pointed to the more evident way of limiting property rights, which was persistent until the $17^{\text {th }}$ and $18^{\text {th }}$ centuries in Europe and which is still a problem for many developing countries. Governments usually exercised arbitrary powers mainly through brute force or manipulation of judicial power. Expropriation of private wealth took place both through physical dispossession and through forced loans and credits to the government which later defaulted. Under such regimes, the incentives to invest in capital or get an education or innovate were weak. The allocation of resources was distorted because talent, effort and financial resources that could finance improvements were channeled to other uses with lower social returns. This basic insight has inspired recent works by Acemoglu, Robinson and Johnson. In Acemoglu, Robinson and Johnson (2001, 2002, 2004, 2005) and Acemoglu (2005b) the authors emphasize, either while explaining their empirical strategy or when discussing important features that a theoretical model should stress, the importance of "good institutions". They define "good institutions" as those protecting property rights and measure them through the 
"protection against the expropriation risk". They argue about the influence of such a risk on investments and the creation of new wealth and empirically demonstrate that such institutions have positive effects on growth, investments, and financial development.

Acemoglu and his coauthors are not the only ones who explored the effect of expropriation risk and unrestrained power of rulers on growth. De Long and Shleifer (1993) measure economic growth through the expansion of cities during the Middle Ages and the Renaissance until the end of the $18^{\text {th }}$ century and divide political regimes into “absolutist” and "non absolutist". Their conclusion, supported empirically, is that under non absolutist regimes, the cities grew more than under absolutist regimes. Their theoretical model once more refers to the lack of private investments and entrepreneurship due to the lack of protection of individual rights.

To these historical studies we can add those models and regressions that examine the effect of military coups and political revolutions on growth and investments. Coups d'Etat or military revolutions significantly raise the likelihood of confiscation and limitation of individual liberties. They could influence economic growth through some channels other than infringing on individual property like closing the possibility of foreign trade, reducing the education level in the country or distorting resources toward less efficient uses. Nevertheless, one of the main problems given by political instability and the threat of military coups and revolutions is the expropriation risk that reduces investments and leads to lower growth rates. This is a relevant problem in many developing countries today.

There is a disagreement between economists and political scientists on the importance of coups. Barro (1991) finds a negative and significant coefficient for military coups and revolutions in his cross-country regressions; he suggests that the likelihood of a military takeover may have a negative influence on growth. Londregan and Poole (1990) employ a time-series analysis and find a similar negative correlation between growth and the likelihood of a military coup, although they conclude that the causality runs in the opposite direction, from economic crises to revolutions, while coup history and the 
current propensity for Coup d'Etats have no significant effect on growth. This discrepancy can be attributed not only to different econometric strategies, but also to the endogeneity problem that characterizes this type of regressions.

\section{Inefficiencies and Corruption of Civil Servants}

Economists have pointed to a further mechanism that is likely to infringe on private property rights. Inefficient or corrupt civil servants hamper individual rights to property, create uncertainty and cause misallocation of resources.

It is important to note the differences between this second case and the previous one. In the first case, the risk of expropriation reduced the returns on all those activities that required investments, irrespective of whether in physical or human capital or research activities. In addition, this second channel works through the misallocation of resources, both human and financial ones. Weak enforcement of property rights in this case creates a rent-seeking sector. Such sectors, "particularly rent-seeking by government officials" (Murphy et al. 1993), are particularly harmful for growth because their goal is not to create wealth but just to redistribute it (Olson 1965). There are many common points among the two literatures, but describing them separately is still worthwhile.

Murphy, Shleifer and Vishny (1991, 1993) suggest that most talented people organize production carried out by others rather than producing themselves, thus spreading their abilities on a larger scale. In their model, each individual has two choices. He can either become an entrepreneur, starting a firm, and innovate and produce growth or become a rent seeker who redistributes wealth to himself. The occupational choice obviously depends on the relative returns to each activity. Such returns are influenced by three factors, the size of the market, the degree of diminishing returns to scale and the compensation contract. The last just describes how much of the surplus an entrepreneur can appropriate. If the returns to innovation are not protected and cannot be captured by the innovator, entrepreneurship becomes less profitable. 
Bad institutions driving individuals toward rent-seeking activities harm economic growth for several reasons. First, rent-seeking sectors absorb labor and other resources. Second, the "tax" imposed by rent-seekers on productive activities further reduces the incentive to innovate. Finally, when the quality of entrepreneurs decreases, the rate of technological growth is reduced.

Acemoglu (1995) builds a model where the compensation contract is "endogenous". It is influenced by the allocation of individuals across the productive and rent-seeking activities. The rents producers expect to pay diminish the profitability of productive investments and hence, their attractiveness. This result is reinforced in the dynamic version of the model which displays path dependency and multiple equilibria. As the rent-seeking sector grows, the incentives to be entrepreneurs weaken and the economy may get trapped in a "rent-seeking” steady state.

Acemoglu and Verdier (1998) elaborate on a general equilibrium model that contains agents in the public sector accepting bribes to enforce contracts between private parties. This paper formalizes two possible distortions arising from corruption. Weak enforcement of contracts due to the presence of bribes reduces the incentive to invest. Meanwhile, increasing returns in the rent-seeking sector attract agents with no comparative advantage for this sector (misallocation of resources). This model is interesting for another reason. It contains the idea that weak protection of property rights might be an equilibrium property, and it reaches a somewhat surprising result. Less developed economies may choose lower levels of property rights enforcement due to the lower productivity of their investment opportunities. Such a conclusion is perhaps too extreme if the theory discussed in this paper is true. Investment opportunities are more likely to have low productivity because property rights are not sufficiently protected, not vice versa.

Other authors also consider the problem of rent-seeking behavior but do not consider the problem of talent allocation. Moreover, these works are not focused on property rights; hence they will only be briefly mentioned. Magee, Brock and Young (1989) illustrate the 
predatory behavior of more organized groups towards less organized groups that reduces economic growth.

\section{Taxation}

Ownership protection is diminished by taxation. Governments provide different services to society and collect resources in order to achieve their goals. The distortions on individual behavior caused by the tax system should be compared to the benefits originating from the services provided by the State. Contract enforcement, or the same protection of individual rights, is paid with the resources appropriated by the public administrations.

A simplified version of this mechanism is well illustrated in two papers by Alesina and Rodrik (1994) and Persson and Tabellini (1994). Agents act as consumers and voters and taxes are used for redistribution from rich to poor agents. When deciding on the equilibrium tax level, the median voter (both models feature a median voter type of political environment) must balance two effects. On the one hand, the higher the tax rate, the higher the redistribution from rich to poor agents. On the other hand, the higher the tax rate, the lower the returns on private investment, the lower the investment and growth and hence, the amount of resources available for redistribution in the next period. The main result of these two studies is that more inequality and a poorer median voter imply a higher level of taxation and a lower growth rate in the long run. The higher is the tax rate, the larger is the expropriation of private wealth and the less protected are the private property rights.

\section{Barriers to Technological Adoption}

Economic growth presupposes technological progress. This suggests that economic institutions that discourage either the production or the adoption of new technologies have a negative effect on economic development. This idea is pursued by Acemoglu (2005a) and by Parente and Prescott (1994, 1999). Existing producers or workers can 
form a coalition to block the entry of new producers with a better technology in order to protect their rents.

Parente and Prescott follow this line of reasoning in two papers. Parente and Prescott (1994) are less careful than Acemoglu (2005) in modeling the political arena and the way societies may take decisions. They simply refer to "barriers [that] take different forms such as regulatory and legal constraints, bribes that must be paid, violence or threat of violence, outright sabotage and worker strikes” without specifying the social or political processes or cultural characteristics that determine such barriers. Moreover, they highlight the role of workers as potential beneficiaries of barriers to technological adoption. In the other paper, Parente and Prescott (1999), the authors focus on a specific mechanism, monopoly arrangements in the market of factors suppliers, that obstruct technological adoption and growth.

Acemoglu (2005) distinguishes between two types of societies. First, the oligarchic society where the political power is held by a restricted group of producers who use it to erect barriers to the entry of new competitors. This equilibrium is "good" in terms of growth in the short run, because the producers that are likely to become dominant in the first place are the most productive and because taxes are set at a very low level. As time goes by and their technology becomes obsolete, the lack of entry of new producers is likely to cause a slowdown in the rate of economic growth.

Democratic societies have higher taxes, but lower barriers to entry. In the short run, these societies may lag behind the oligarchic ones because high taxes discourage investments. As time elapses and new technologies become available, the entry of new entrepreneurs improves the overall productivity of the economy and increases the rate of growth. Eventually, democratic societies overtake oligarchic ones.

There are three points worth noticing in Acemoglu's paper, which will be discussed in the following subsections. The first point is the attention to the political process and the idea that the protection of property rights is an equilibrium outcome that depends on the 
relative forces of different actors. The second is the focus on the form of property rights, and the distribution of such rights. The last point is the idea that by creating high entry barriers, incumbents are effectively restraining the property rights of new entrants, which negatively affects the growth rate. Acemoglu suggests that entry barriers can be viewed as a way of limiting the property rights of future entrepreneurs.

\section{Further Considerations}

A crucial aspect that economists tend to underestimate and do not explicitly treat in their models is the "form of property rights" (Acemoglu 2005). The interplay between protection of property rights and the distribution of economic resources may be important.

The basic intuition behind the theory of property rights is based on economic incentives. Property is beneficial for growth because it allows every individual to receive the returns on his effort and talents. They align private and public costs and benefits. Implicit in this line of reasoning is the premise that the individual should always have the "right" incentives thanks to good economic institutions. The question is to what extent these incentives depend on the distribution of resources in society. To give an extreme example: What type of incentives does an individual who owns an entire country have to make an "optimal” amount of investment? Would this cause underinvestment and hence, low growth? Can we say that in this case, the protection of property rights does not provide a sufficient stimulus to economic growth?

The economics literature is not sufficiently developed on this account. Acemoglu et al. (2004) state that "we think of good economic institutions as those that provide security of protection of property rights and relatively equal access to economic resources to a broad cross-section of society. Although this definition is far from requiring equality of opportunity in society, it implies that societies where only a very small fraction of the population has well-enforced property rights do not have good economic institutions”. The authors do not go much further in explaining why an equal access to economic resources is better than an unequal one. Nevertheless, the suggestion is that the protection 
of property rights is a necessary rather than a sufficient condition. It seems that the distribution of property rights plays an important role, even if the authors are not clear about why and how it does so.

A paper explicitly modeling the distribution of ownership is Galor, Moav and Vollrath (2004). The model is meant to capture the transition from agrarian societies to industrial economies and the divergence across different countries. The key factor is the distribution of land ownership. Regions characterized by an unequal distribution of land are likely to resist the transformation to modern industrial economies, while those with more equally distributed land holdings are more prone to adopt the industrial model. The key to successful changes in economic institutions is given by the degree of complementarity between human capital and land and human and physical capital. Human and physical capital are strong complements, while the complementarity between land and human capital is weak. An increased level of education increases the cost of labor beyond the increase in average productivity in agricultural sectors. The adverse effect of the implementation of universal public education programs on landowners' income is magnified by the degree of concentration of land ownership. In a political system where the large landowners also controlled the political power, public education programs were rarely adopted. On the contrary, in territories where labor was scarce and land abundant and evenly distributed, there were no powerful interests opposing public education. Universal education later revealed itself as a powerful engine for growth. The theory proposed directly addresses the question of how the distribution of property rights and resources may affect economic growth. The author proposes a specific political channel for the causality, from land distribution to education and human capital accumulation.

There is also research in this field on third world countries, in addition to historical examples related to western countries. De Soto argues in two different books, The Other Path and the Mystery of Capital, that countries in Latin America and Africa or Asia are poor due to bad property rights institutions. Most of the capital of the country is left outside the legal framework that guarantees ownership and the transferability of titles. 
His conclusion echoes Acemoglu's claim that societies where only a small fraction of the population enjoys legal protection of property rights lack vital institutions required for high rates of growth.

Grossman and Kim (1996) do not address the relationship between the distribution of property rights and growth but, closely enough, the channel from distribution of resources to property rights and welfare. The initial distribution of human capital affects the probability of predation by the poor and the amount of resources invested in protection activities. A more egalitarian society, one with fewer people with low levels of human capital, implies a lower investment in protection. More inequality, on the other hand, ensures that rich people invest the amount of resources necessary to prevent predation by the poor. This paper is interesting in the link it proposes between the distribution of resources and property rights. There is no State that enforces property rights in this model, there is no political arena where different interests can clash and compete for political power. The only thing individuals can do is to invest in their own protection. It might be optimal for an individual to tolerate diminished protection of his property, given the difference in wealth distribution. This model completely lacks a theory of inequality and economic growth and inequality. Hence, its predictive power is limited. The same idea can instead be elaborated in a framework where inequality is partly endogenized to study how it influences growth.

A model on the distribution of property rights should consider different aspects. The distribution of property rights may influence economic growth, either through economic or political channels. It may affect the optimal amount of investment or determine the relative power of different groups. The focus obviously depends on the question we would like to answer. When looking at historical examples, it may be more relevant to consider political aspects of the distribution of property rights. Historical examples are usually those related to large changes in political regimes through revolutions or coups. When looking at differences among modern western countries, simple economic aspects may become more relevant. 
The distribution of property rights may affect the economic incentives of individuals. Economic aspects of the distribution of property rights are probably related to the optimal amount of investments or the efficient use of resources allowed by more or less concentrated property rights. It may also influence the likelihood of innovation. On the one hand, if property is more dispersed, more individuals are likely to invest in research and development. On the other hand, more concentrated ownership leads to more resources invested in such activity or greater returns.

The distribution of property rights can be relevant in terms of the distribution of political power. Acemoglu et al. (2004) describe different sources of power. Written laws and political institutions are sources of what they call the "de jure" political power; different classes control different political bodies and use them to favor redistribution of resources toward themselves. This is only influenced by current institutions and has no relation to economic resources. Nevertheless, there is another source of political power, the one that Acemoglu and his coauthors call "de facto" political power. They do not only refer to cooperation among individuals and hence the capacity of overcoming the collective action problem, but also to economic resources that can be used to finance lobbying or maintain an army. Both sources of political power contribute to the final outcome of the social conflict that the authors consider to be the main determinant of present and future institutions. Distribution of resources may influence future institutions because it affects the "de facto" political power today.

This section will conclude with two further remarks. It is possible that the distribution of property rights may change in relevance, depending on the main source of economic growth. Some economists have pointed out that the source of economic growth has become more "intangible" during the course of history; from land, a physical factor of production in fixed supply, to capital, which embodies technology and is easily reproducible, to human capital, which is very difficult to capture and expropriate. Ideas have always been the engine of growth but now the intangible sectors, services in general, have come to represent the greatest part of modern western economies. 
It is not unreasonable to conjecture that the distributional issue of property rights decreases in importance as ideas and talent increase in importance. Juhn, Murphy and Pierce (1993) argue that the increasing inequality in earnings witnessed by the two last decades is due to the increasing importance of skills in modern economies. Human capital and ideas are less likely to be excessively concentrated. Economists do not agree on the direction of such an impact and policy measures to be taken to cope with it (e.g., the debate on patenting of strings of computer programming or biomedical innovations), but they all agree on the importance of such transformation ${ }^{2}$.

The second point, already extensively discussed in the literature on property rights, is the possible endogeneity arising in such questions. The distribution of property rights influences growth but growth and wealth creation may influence the distribution of resources. A simple example is given by the Galor et al. (2004). As the economy grows, land become less important, education and human and physical capital become more important, while the price of labor goes up. This has immediate distributional effects: What is of importance is not land ownership but personal talent, social capital and organizational abilities.

\subsection{Institutions as Equilibria}

The last argument to be discussed in this section is the rise and persistence of various political and economic institutions. At the beginning of this paper, it was briefly explained that there are mainly three alternative explanations. Institutions are efficient collective arrangements in a given environment, the result of ideology and culture or the product of social conflict among different classes. I will focus on the social conflict theory because it seems to have a major explanatory power and because it is common among economic authors.

The social conflict view can explain how some institutions were established before and during the industrial revolution. Nevertheless, it lacks explanatory power when it comes

\footnotetext{
${ }^{2}$ I would like to thank Magnus Henrekson for pointing this out.
} 
to important questions such as why they emerged in some countries and not in others, or why they still remain undeveloped in poor countries today. I will later complement the social conflict view with some ideas and results that emphasize the role of culture and social norms.

Some authors emphasize the mechanisms that led to the rise of property rights institutions; most of the literature tackles the more general issue of the rise and persistence of political institutions in general. According to some scholars, institutions are "state variables" chosen in this period for the next one. Obviously, such a choice will depend on their effect on those who have decision-making power today. The idea is that institutions are endogenous in the long run, but exogenous in the short run.

Since this paper is not about the theory of political institutions, it will not provide a complete and exhaustive overview of social conflict and cultural theory of institutions, but it will refer to them as long as they are useful to understand the property rights evolution.

\section{Social Conflict View on Institutions}

It is common among economists to view institutions as equilibrium outcomes. Different scholars have identified different sources of political institutions and different mechanisms through which they are established, especially property rights institutions. Indeed, in previous sections, we saw papers that considered them as an optimal arrangement among different classes (e.g., Acemoglu and Verdier 1998, Parente and Prescott 1994, Galor, Moav and Vollrath 2004 and Grossman and Kim 1996). Such papers considered the idea of property rights as an equilibrium outcome but, in general, were not centered on modeling such an equilibrium. The following ones have been more careful in the characterization of the political processes leading to property rights protection (or the lack thereof).

These theories are not only about how institutions come into existence, but also about the persistence of institutions. Economies can be stuck in some bad equilibrium because 
some parts of society control political institutions that preserve their power, and result in slow growth.

Sonin (2003) discusses a case where the rich may benefit from low protection of property rights, inspired by the Russian oligarchs of 1990s. The key idea of that model is that public and private protection of property rights are to some extent substitutes. If the government does not provide enough protection, individuals must invest more in private protection. The ability to maintain private protection because of substantial economies of scale in private protection technology makes the rich natural opponents to public property rights protection; they can, in fact, protect their own assets and, at the same time, predate over the assets of poorer individuals through rent-seeking. It is worthwhile for them to manipulate institutions in order to achieve a low level of public protection of property rights. This prevents the formation of market-friendly institutions that would promote growth. Such economies can remain stuck in bad economic equilibria characterized by widespread rent-seeking, weak protection of property rights and slow growth.

Another paper reaches a quite different conclusion. Sonin (2003) argued that the rich may have incentives to limit the protection of property rights and keep the majority of the population in poverty. Bourguignon and Verdier (2000) discuss the case of an oligarchy that adopts policies favorable to economic growth in order to protect its future property rights. Growth and political participation are in their view driven by education. High inequality may lead to low political participation of the poor, but also to a poorer median voter demanding more redistribution. The elite can adopt two strategies: it can predate on the poor, keep the inequality and oppose any reform that may reduce its future political power. Or, it can favor education programs in order to foster an educated middle class that will boost economic growth and reduce the risk of future expropriation.

The simple comparison between these two models tells us that the way economists model incentives and the reward-structure of the elite may lead to different conclusions regarding its role in promoting or hindering institutions favorable to economic growth. 
Still another approach is proposed by Krusell and Rios-Rull (1996). They propose a theory of stagnation and growth driven by the incentive of the majority of voters to favor technological innovation. The idea is similar to the ideas of Acemoglu (2005a) and Prescott and Parente (1994, 1999). Vested interests partly responsible for technological adoption can block the entry of new technologies in the economy, thereby slowing the growth process.

In this model, agents can be skilled managers or unskilled workers. The skilled agents can either innovate and produce a new technology, facing some costs, or learn old technologies, paying a lower price. The technological adoption process is simple: in each period, the economy votes on the adoption of a new vintage of human capital (produced by those agents who chose to be entrepreneurs two periods previously). Depending on the distribution of skills, the economy can grow forever or oscillate between stagnation and growth or never innovate.

Svensson (1998) finds that political instability leads to poor protection of property rights and hence, to underinvestment and low growth. Reforms necessary to improve the legal framework of a country are costly and the benefits are not completely internalized by the incumbent government. Governments in this model are only interested in maximizing the welfare of their constituencies. They will bear all costs of a reformed legal system but future benefits will also accrue to the other political party. Moreover, a poor legal enforcement of property rights will reallocate resources away from taxable income. Future governments will not be able to collect and spend large amounts of money. These effects are stronger the more unstable and polarized is society. In this model, classes are not defined as previously in rich and poor or elite and disenfranchised, but more generally as political constituencies.

Acemoglu et al. (2004) do not present a specific formal model of property rights protection but present a theory of institutions as a result of social conflict among classes. The authors state that current economic performance is influenced by current economic institutions which, in turn, are determined by current political institutions. The latter have 
been established in the preceding period and represent the equilibrium of forces among classes in the previous period. At the same time, the economy will today choose political institutions that will prevail in the next period. The choice of future institutions will depend on the relative power of different social groups. There are two sources of power. The "de facto political power" represents available economic resources and collective action solutions for each class. "De jure political power” entails legitimate decisional power over current policies given by current institutions (see Acemoglu and Robinson 2006a for a more complete discussion of these two categories of political power).

This framework is quite general and can be applied to different historical examples and theoretical cases. Acemoglu and Robinson explore its many possibilities. Going from verbal arguments to more formal settings, they use it to explain economic institutions regulating the labor market (Acemoglu and Robinson 2006b), the extension of the franchise to the poor masses in Europe and in Latin America (Acemoglu and Robinson 2001, 2002) and the existence of political losers as barriers to economic development (Acemoglu and Robinson 2000).

Acemoglu (2005b) proposes a model explaining the persistence of inefficient, nongrowth enhancing institutions, based on the same intuition. All these papers differ in their details and specific modeling strategy, in the questions they try to answer and in the emphasis put on different elements. Nevertheless, they are all based on the same fundamental idea that the distribution of political power today is of importance for institutions tomorrow.

Two immediate and common comments on these attempts are the following. First, economists are still missing a complete and shared formal model of the establishment of property rights. The papers on institutions and institutional change and persistence are useful for considering the dynamics that influence political institutions. Nevertheless, they leave too many questions still open on current institutions and possible policy measures. Having said that institutions tomorrow depend on political power today, what are the real policy measures we can suggest and adopt in poor countries to make them 
grow? Considering that one cannot replicate the historical conditions prevailing in England in the $17^{\text {th }}$ and $18^{\text {th }}$ centuries, what are the main implications of economic studies on policies?

Second, this literature suffers from the same limitations as other political economy models. The results obtained are heavily dependent on the form of the model, the structure of the payoffs and assumptions on collective behavior. An aggregation theory starting from more basic assumptions about human behavior that can deliver an aggregate political behavior is still lacking. This is in particular true for the case of non democratic regimes.

Economists have proposed different theories of growth and protection of property rights. They provided a guide for the empirical tests of such relationship. After this general overview of the theoretical literature, we can then turn toward the description of the empirical attempts to isolate the effect of protection of property rights on economics growth.

\section{Secure Property Rights Are Beneficial for Growth: Some Evidence}

It is not hard to find empirical attempts to identify the effect of protection of property rights on growth. As we have just seen, private ownership may affect growth through numerous channels. This includes favoring the accumulation of physical capital, improving the quality of physical capital used in production through technological improvements and improving the quality of the labor force through education and accumulation of human capital. Identifying all these separate effects in the data is not an easy task because of measurement problems of concepts like human capital, and because of possible arbitrariness in the definition of "protection of property rights". Measurement problems are not the only difficulties researchers must deal with. Missing variables and endogeneity are other problems confusing the empirical estimates. If good institutions enhance growth, it is also possible that as the average income of a society increases, 
individuals will ask for more efficient institutions and more secure property rights. It is also possible that there may be a variable missing in the analysis that influences both economic growth and the quality of institutions (such as "culture"). To overcome these possible shortcomings, an instrumental variable approach is usually applied, with the empirical strategy of finding a workable instrument for the purposes at hand. But the choice of instruments is not obvious and economists often question their validity.

The studies can either consider the link between growth and property rights at the macro level, based on cross-country analyses (e.g., Hall and Jones 1999 or Rodrik et al. 2004) or at the micro level, considering the choices of single individuals (see Besley 1995). They can either rely on "objective” measures of property rights provided by some institution like the Freedom House (Rodrik 1995), constructed by themselves (Besley 1995) or use some questionnaire that gives a "subjective" assessment of protection of property rights (Johnson et al 2002). Economists can focus their attention on correlations between rates of growth and institutions (De Long and Shleifer 1993) or between differences in income levels and institutions (Hall and Jones 1999). Economic growth is captured through direct measures of changes in output or, more commonly, through a measure of "investments" that is easily found and is theoretically an important determinant of economic growth ${ }^{3}$.

The results obtained by all these studies are that property rights are of importance for growth and that most of the differences among countries today in terms of productivity per worker or income per capita can be explained by institutional differences.

\subsection{Description and Limitations of Empirical Research}

Micro studies are usually more reliable in terms of the validity of their results, as they avoid the problems related to the aggregation of data. Johnson et al (2002) use a survey conducted among entrepreneurs of former communist countries in order to study the effect of weaker property rights on reinvestment of profits. They find that firms are more

\footnotetext{
${ }^{3}$ I will disregard two important strands of research, namely the protection of intellectual property rights and the role of human capital.
} 
likely to reinvest their profit if they perceive their property rights as more secure, with secure property rights being more important for investments than availability of credit. Another paper using a micro approach reaches a similar conclusion. Besley (1995) shows that farmers in Ghana are more likely to plant additional trees if they perceive their property rights as more secure. The study of Besley is particularly interesting because the author discusses the possibility of an endogeneity problem in a micro setup. In rural communities in Africa, property rights are more secure the more the farmer invests; investments may strengthen his rights in the view of the rest of the community. Micro studies tend to be less likely to suffer from the endogeneity problem that is typical when using aggregate data (especially in a historical perspective). A critique, however, is that neither of these studies assesses the possibility of a missing variable problem.

An indirect confirmation of the benefits of secure property rights on investments and growth is given by La Porta et al. (2002). They study financial decisions of investors and creditors over firms in the stock market. When the rights of outside investors (both shareholders and creditors) are better protected by law, investors and creditors are willing to invest more money or, equivalently, pay more for financial assets. A law protecting the property rights of outside investors raises the return on financial investments in such firms; hence, the price investors are willing to pay for such assets. The authors construct a theoretical model along these lines and test it successfully using a sample of 539 firms from 27 developed economies.

Even if a good deal of insight can be gained from micro studies, it is natural to use crosscountry regressions to assess the impact of protection of property rights on economic growth, since countries differ both in terms of economic institutions and income levels (a result of past growth rates). This creates a reasonable 'natural experiment'.

Researchers who use cross-country analyses are well aware of the potential problems of this approach; the main problems being endogeneity and omitted variable concerns. That the role of economic growth or the level of income may have an effect on the quality of institutions should not be a surprise. First, richer individuals are likely to demand better 
institutions and better protection of their properties. Second, Acemoglu and Verdier (1998) argue that unfavorable institutions are an equilibrium outcome for countries with low productivity investments; in this case, a third element, the low productivity of investments, determines both the low quality of institutions and the low growth rate of the economy. Third, in an empirical paper, Chong and Calderon (2000) find that the poorer the country and the longer the time before good (growth enhancing) institutions are established, the higher is the influence of institutions on economic growth. They also report that, once institutions favorable to economic growth are set up, economic development stimulates improvements of the quality of such institutions.

Finally, Rodrik (1999) presents a mechanism of transmission of economic shocks that goes through political institutions and affects economic growth. He argues that the economic shocks of the mid-seventies had different impacts on different countries because of the difference in the suitability of national institutions in dealing with the shocks. Countries with deep social divisions and weak conflict-management institutions were unable to adopt the correct measures to contain the negative effect of economic shocks and remained locked in a bad equilibrium. But the same macroeconomic shock did not have a long-lasting impact on other countries. The first group got stuck in a situation with bad institutions and bad growth.

Faced with the risk that endogeneity or omitted variables biases the results, researchers usually resort to using instrumental variables. The problem with the IV strategy is that the choice of instruments is often subject to controversy. Moreover, even a suitable instrument may not say a great deal about the causal relationship between two variables.

Mauro (1995) explores the relationship between corruption and growth. The author constructs various indexes of corruption from several measures taken from "Business International”, a unit inside "The Economist Intelligence”, and regresses them on growth rates and investment rates. He finds a negative association in both cases. Such a result does not imply a clear-cut causal relationship. More corruption can be the result and not only the cause of lower growth. To take care of this problem, the author uses an index of 
ethnic fractionalization as an instrument for corruption. The limit of this instrument, in turn, is that ethnic fractionalization, while perhaps correlated with corruption, can also be directly correlated with growth and investment, or may affect them through other channels than corruption.

\subsection{Successful Instruments}

A famous paper by Hall and Jones (1999) investigates a model where the "social infrastructure(s)" of different countries explain their differences in relative productivity levels. Broadening the meaning of institutions, they add government policies to the definition of social infrastructure (in addition to the rules, norms and political organizations of society). The main finding is that better institutions have a positive effect on growth, but it is necessary to correct for the possible endogeneity. Their instruments are meant to capture the influence of European culture on the country considered (assuming that European culture had a positive effect on local institutions). Those instruments include geographical distance from the equator, as Europeans were more likely to settle in regions far from the equator. The percentage of populations speaking a European language as their first language is also used as an instrument. Once more, these instruments can be criticized. Geography may affect growth through other channels, for example climate and distance (even if more recent papers have found this effect to be weak) and the fraction of the population speaking a European language may at least partially be endogenous. Perhaps Europeans tended to settle in more successful countries, and residents in more successful countries may have been more likely to learn European languages.

One of the most convincing empirical papers finding a positive relationship between the protection of property rights and economic growth is Acemoglu et al. (2001). The authors call "good institutions" those protecting private property and reducing the risk of expropriation from the government. Their analysis is restricted to former European colonies, as colonization is considered a natural experiment that can allow us to evaluate the impact of institutions on economic growth. Their theory says that Europeans 
established different institutions in different colonies based on mortality rates. Where the risk of death was higher the Europeans established extractive institutions, which did not guarantee property rights. At the same time, they created institutions that protected property rights whenever they expected to settle for a long time. That paper is complemented by another by the same authors (Acemoglu et al. 2002) where they complete the picture by also adding the density of the native population and the abundance of natural resources. These factors are found to determine whether the environment was favorable to exploitation or "property right institutions".

In their view, exogenous elements (such as the disease burden or the density of population in overseas territories) determined the type of institutions that was established and not other elements like culture or religion. Moreover, institutions and not geography are the main determinants of economic growth. The only effect of geography is through the determination of the likelihood of Europeans to settle in a given region. This theory has stood up to many tests and has become quite successful.

Rodrik et al. (2004) contrast and test the three main theories of growth, geography, institutions and trade, using the instruments proposed by Acemoglu et al. (2001). They took advantage of these instruments and the one presented by Frankel and Romer (1999) for international trade, calling them the best instruments available for institutions and trade integration: "these two instruments, having passed what might be called the American Economic Review (AER)-test, are our best hope at the moment of unraveling the tangle of cause and effect relationship involved”. The conclusion reached by Rodrik et al. (2004) is that "institutions trump geography and openness".

\subsection{Final Remarks on the Empirical Evidence}

Despite settler mortality being a very successful instrument, some caution is due when we come to the interpretation of the results. A motive of prudence is explained by Rodrik et al. (2004); after declaring the success of institutions over geography and trade, the authors argue that "an instrumentation strategy should not be confused with building and 
testing theories”. The fact that settler mortality has proven to be a good instrument does not say much about the rest of their theory, in particular about the role of colonial policies in explaining differences in income per capita across the world; as noticed, Acemoglu and his coauthors fail to carry on direct tests of the impact of colonial policies and institutions and obviously, such a theory does not explain income differences across countries that have never been colonized by the Europeans.

In section 5, I will propose another reason for caution in the interpretation of the results reached by Acemoglu and his coauthors.

This paper did not cover all the possible specifications and regressions that have been run on our topic of interest. I only considered a representative sample of the empirical research in the field. Many studies on protection of property rights and patenting, investment in research and development and education, or the micro studies covering single policies such land tilling in specific regions of the world were not surveyed.

The empirical evidence is generally highly supportive of the theory and the intuitions that tell us that more secure property rights are conducive to economic development and rising income levels. Nevertheless, the entire range of possible econometric shortcomings of such regressions should be kept in mind.

\section{Where Do Institutions Come from?}

A powerful and indirect critique to the social conflict view comes from those papers exploring the role of culture in explaining the rise and persistence of institutions. By culture, economists usually mean a set of common beliefs, values and shared ideas about society and its members; common practices and behavior to which people adhere and expect to be followed by others in specific contexts.

According to Bednar and Page (2006a) "Culture can be defined as individual and community level behavioral patterns that depend upon context and are often suboptimal. Cultural behavior influences the performance of institutions [...] the efficacy of markets, 
democracies, and law hinges upon behavior, particularly the tendency for people to cooperate with and trust one another. A theory of institutions, therefore, must come to grips with culture”. Bednar and Page (2006a, 2006b) develop a theory of persistence of institutions through the cultural mechanism. Culture determines the form of institutions by influencing the performance of different institutions. Common beliefs may also induce the particular equilibrium among the possible ones given by a combination of institutions that is chosen. On the other hand, institutions produce culture through "institutional externalities”. Institutions create behavioral regularities which, in turn, form part of the culture. The authors also claim that the order in which different institutions were introduced is important. Bednar and Page distinguish between "phat dependence”, culture depends on the institutions existing at some point in time, and "path dependence", the order in which the institutions are introduced is also of importance. This explains the claim at the beginning of this paper about the extension of the franchise during the $19^{\text {th }}$ century. This extension came after the introduction of liberal institutions and hence, was unlikely to upset the overall institutional arrangement.

Bednar and Page are not the only authors that underline the importance of culture. There is a vast literature that assesses how culture profoundly affects institutional performance (e.g., Putnam 1993, Chong 2000 and Huntington 1981). North (1990) also appeals to the importance of culture in institutional performance.

Greif (1994) analyzes two groups of merchants, the Genoese and the Maghribis, operating in the same historical period, in the same markets and using equivalent technologies. He attributes the profound differences in institutions governing their business affairs to their different cultures. The first, part of the Latin world, had an "individualist" culture leading to modern institutions that allowed them to win the competition in the Mediterranean. The latter, belonging to the Muslim culture, had a "collectivist" culture that prevented them from taking advantage of all opportunities offered by the Mediterranean trade. 
This brief and far from exhaustive presentation of the literature on culture serves the purpose of substantiating some doubts about the social conflict approach. It seems that social conflict is an excellent approach for explaining the timing and the specific form assumed by institutions. At the same time, it needs to be complemented by an analysis of how culture influences those same institutions. To pose a direct question: Where are the individual rights and liberties, the idea that the individuals and their freedom matter more than anything else? We have seen merchants and small landowners in all historical periods and in all cultures. They always tried to defend their interests and find more space for their business but only in the $17^{\text {th }}$ and $18^{\text {th }}$ centuries did these interests lead to Parliamentary supremacy and the Rule of Law. Is it because those merchants and landowners had a different idea about the importance of individual freedom? If we try to explain the liberal revolution just by some social conflict argument, we risk missing an important part of the story.

The idea is twofold. On the one hand, culture can help us explain how the institutions were shaped, why countries chose particular arrangements and why other countries cannot adapt to the "best" institutions. On the other hand, cultural transmission mechanisms can explain the persistence of political institutions. Persistence of institutions is not only due to the conflict among different classes, but also to the adaptation of individuals to particular institutions. The process of change for institutions is not only slowed by the resistance of political losers but also by the cost of changing individuals' values and norms and behaviors and expectations over others' actions.

\section{Culture and colonization}

The cultural hypothesis may be used to challenge the idea put forward by Acemoglu et al. (2001). This paper claims that exogenous elements (the density of population and the settler mortality) determined the form of institutions chosen by the Europeans across different colonies. I instead argue (Asoni 2006) that it is not necessarily true that "culture” can be completely discarded (as that paper claims after controlling for religion and the nation of origin of the settler). 
Taking a quick glance at the European cultural heritage of different colonies, we cannot avoid noticing that the more successful colonies are also those with an English colonial background, while none of the former Spanish or Portuguese colonies have reached the same level of development. Moreover, in my opinion, it is not sufficient to point out that some of the former British colonies did not develop to the same extent as the United States or Canada or Australia, or that some colony with a non-British cultural heritage developed as much as or more than other British former colonies. After all, the theories and empirical evidence should not be interpreted deterministically. The purpose is to explain the relative likelihood of being more developed.

Is it reasonable to presume that the English were just "lucky" and happened to colonize territories where they encountered conditions favorable to the creation of good institutions, while the opposite happened to Spanish settlers? Is it possible that the English and Spanish, respectively, rather chose to concentrate on certain types of regions, fitting their economic, political and social interests? I imagine that there exists some interplay between the point made by Acemoglu and his coauthors on the incentives to create good or bad institutions and the cultural heritage of the settlers ${ }^{4}$. Moreover, institutions in the colonies were probably influenced by the policies in the motherland. Let us analyze these points one by one.

We should devise an empirical strategy to compare territories, former colonies with similar exogenous characteristics, land-man ratio and disease burden, and calculate the likelihood of such territories being developed (or underdeveloped) under the British, Spanish or Portuguese rule. This is would give us a more precise idea of the importance of cultural heritage and settlers' values and social norms in explaining the development of former colonies. Given the same disease burden, land-man ratio etc, the influence of colonial background can be tested

\footnotetext{
4 "Good institutions" are those beneficial for economic growth, while "bad institutions" are those hindering investments in human and physical capital and economic development.
} 
Theoretically, it is possible to identify at least three mechanisms that could influence the institutions set up in overseas territories differently from the one explained by Acemoglu and his coauthors. First, institutions did not need to be set up from scratch in former colonies. Europeans could simply copy most of the institutional framework created by the native population (usually extractive institutions). In this case, the choice of institutions did not really depend on exogenous factors, but the colonists just adapted to what already existed in a given territory (perhaps because it was an easier way of controlling it). This is pointed out by Acemoglu and his coauthors but they do not emphasize that this factor is separate from the exogenous factors they list as conducive to certain types of institutions. Native populations may have had the same incentives to establish extractive institutions that Europeans would have had. However, this line of reasoning fails to explain why natives living in territories with abundant land and scarce labor failed to establish the same property rights institutions that the Europeans introduced upon their arrival.

The second and third points are interconnected. The theory proposed by Acemoglu et al. (2001, 2002) works perfectly, if we assume that colonists were homogeneous in their preferences and endowments, so that the only thing that was of importance for institutions was settler mortality (or similar factors). But there are reasons to believe that the direction taken by settlers and the institutions they chose to set up could be influenced by other elements, such as culture or overseas policies of European countries.

We can model a "self-selection process of colonists". Settlers with different cultural backgrounds and values, irrespective of their nationality (nationality is only of importance if correlated with such values), may be interested in going to different new territories. Once they arrive at the colony, they will establish institutions in line with their preferences. Stated in very general terms, let us consider a model where potential settlers are divided into different categories. They can differ in their opinions and preferences on property rights protection, in their abilities, in their entrepreneurial attitude and talent and in the way in which they perceive the role of government. These are just examples suggestive of some patterns but certainly not exhaustive or complete. Different settlers 
would then have different preferences about to which colony they would like to go. A specific group of settlers may have a particular preference for a certain overseas territory or for a type (man-land ratio or density of native population) of overseas territory. If, for example, the people arriving in a given colony have the same preference for the role of government or the social importance given to entrepreneurial effort, they will set up institutions consistent with these preferences and subsequently the choice of institutions will influence the rate of economic growth. The Puritans that settled in New England did not have the same preferences for land as the French who settled in the sugar-producing colonies in Haiti, and did not develop the same institutions. It is not necessary that all settlers who like small government and reward entrepreneurial effort go to the United States. It is enough that a larger share of US settlers have preferences for institutions promoting private ownership and secure property rights. Moreover, if this type of settler was more common in Britain than in Spain, then colonies with a British cultural heritage will be more likely to have growth-enhancing institutions.

Imagine there to be two types of colonists, “entrepreneurs” and "rentiers”. It is reasonable to conjecture that rentiers would look for territories with easily extracted resources (population, soil and climate and natural resources). These colonists would not be interested in institutions protecting property rights, but would prefer institutions favoring exploitation. Analogously, entrepreneurs would be drawn to those lands where it was easier to settle down (a climate similar to Europe and obviously less incidence of mortal diseases), use agricultural technology they already knew (once more, similar climate and soil), obtain land without the risk of having to fight with the natives or with other European settlers (vast amount of land and scarcely populated areas). These settlers are then more likely to set up institutions protecting their lands and their properties. As we will see in next paragraph, this type of self-selection could also be encouraged by the specific policies of the colonizer country.

Domestic factors such as institutions (for example, how powerful the king was), culture (such as attitudes toward entrepreneurship), political equilibria and the structure of the economy (the importance of the mercantile class) shaped European countries' policies 
toward the colonies and institutions they were likely to set up in the new world. These factors led European countries to select the territory to colonize, the type of institutions they were going to set up and the type of colonist they were sending overseas. Engerman and Sokoloff (2000) provide some interesting insights. "Spanish authorities adopted the approach of distributing enormous grants of land, often including claims to a stream of income from the native labor residing in the vicinity, and of mineral resources among a privileged few”. Spanish colonization policy was centralized and encouraged Spanish colonists to go wherever there were large rents to be extracted. Once more, from Engerman and Sokoloff (2000) we know that "Spain focused its attention on [...] colonies such as Mexico and Peru, whose factor endowments were characterized by rich mineral resources and by substantial numbers of natives surviving contact with Europeans colonizers". Spain applied "restrictive immigration policies [...] to her colonies”. It seems that institutions in Spanish colonies were extractive not because of settlers' mortality but rather because of a precise choice. Spanish colonists and government (through military conquest) chose the overseas territories that were more profitable for establishing extractive institutions. The counterfactual of this theory is the story of the Spanish colonies in Florida. Spanish settlers arrived in Florida long before any Englishman landed there, but abandoned the land because there was nothing more than flowers. This suggests that Spanish colonists, whether because of culture or because of domestic policies, were looking for something different, such as rapid wealth in the form of silver mines. Engerman and Sokoloff continue: "the contrast between the United States and Canada, with their practices of offering small units of land for disposal and maintaining open immigration, and the rest of the Americas, where land and labor policies led to large landholdings and great inequality, seems to extend across a wide spectrum of institutions and other government interventions”. It is not clear whether this difference is due to the different endowments of land and resources in those territories (as claimed by Acemoglu et al. 2001). Indeed, much of the southern part of Latin America resembles North America in terms of land and climate. I propose that it may be the case that different policies by European countries (themselves explained by different institutions) could induce individuals to emigrate and settle in different places. The restrictive immigration policies imposed by Spanish administrations are suggestive of 
limits on those Spanish settlers that wanted to go to the New World to settle down and create new wealth through labor and entrepreneurship, while encouraging those who wanted to exploit native populations and local resources. Naturally, this does not only apply to the Americas, but also to Africa.

In terms of institutions as the main causal explanation for differences in income levels today, these three arguments do not change the result that institutions are of importance. They may change the interpretation of the origins of institutions. They highlight the difference between overseas institutions that were just the appropriate response to local endowments of resources and social contracts resulting from national culture and domestic institutions, policies and political equilibria (possibly also domestic endowment of entrepreneurs).

The ideas proposed here do not stand in opposition to the research described above but should be seen as a useful step towards understanding the dynamics that led to the establishment of certain types of institutions. The importance of domestic policies and domestic culture, a term that certainty requires further qualification, should not be underestimated while trying to explain the rise, persistence and performance of institutions.

To my knowledge, these points have not previously been considered from the same perspective. They have been discussed from other angles in other papers. Both empirical and theoretical work is needed to understand the extent of the self-selection process illustrated above and the influence of colonial policies. It would be useful to verify, keeping constant the characteristics of single territories, how the nationality of the colonizer, or another instrument for those unobservable characteristics that we call "culture", would change the probability of becoming a developed country in the future for former colonies. 


\section{Conclusions}

Economists have spent a great deal of effort and time on understanding the economic implications of different institutions. In this paper, the focus has been on property rights institutions, and the effects of certain economic factors on political institutions. Economists have made considerable progress in understanding the complicated dynamics that link economic variables such as growth to the political attributes of society. Still, there are many areas where additional research is likely to be successful and fruitful.

The successful instruments employed in the empirical works by Acemoglu and his coauthors and other scholars successfully clarify the role of institutions in economic development. But interpretation becomes harder once we want to explain the sources of such institutions. A theory of self selection of settlers or selection of overseas territories by European countries may deserve some more investigation. The culture of colonizers may have been of importance through a self selection process. It is hard to think that the distribution of settlers and colonists among different territories was random and that the settlers were homogeneous with respect to their attitudes and objectives. The theory proposed instead hinges on such differences to explain the various institutions that emerged in the former colonies.

Different theoretical papers exist on the rise and persistence of political and economic institutions. The approach considered here was the "social conflict view", a powerful and widespread modeling strategy. Important contributions are from papers highlighting the role of conflict and competition among different classes in determining the shape of the political institutions. The mechanisms presented by the authors are plausible but appear to be excessively dependent on specific modeling approaches. This is probably due to the lack of an aggregation theory for political preferences which is "natural" given the fact that aggregation of political preferences really depends on the political institutions in place. 
A different type of critique came from the literature that focused on culture as a main determinant of political processes. Given the documented importance of culture and the interplay between culture and institutions, only focusing on the specific interests of classes may be too restrictive. Social classes try to shape institutions in the way they prefer. At the same time, institutions are not created in a laboratory but come from common practices and shared beliefs. The outcome that their performance depends on how well they interact with people's behaviors points in the same direction. If institutions are chosen by social classes, then it is probably the case that they are chosen to cope with culture.

Abusing a term previously used in this essay, it looks like the social conflict view is able to explain the mechanics of the rise of some institutions, but that a cultural approach may be more suited to explaining the nature and principles of such institutions. 


\section{References}

Acemoglu, D. 1995. Reward Structures and the Allocation of Talent. European Economic Review 39(1): 17-33.

- 2003. Why not a Political Coase Theorem? Social Conflict, Commitment and Politics. Journal of Comparative Economics 31(4): 620-52.

Cambridge, Mass.

2005a. Modeling Inefficient Institutions. Working Paper no 11940 NBER, 2005b. The Form of Property Rights: Oligarchic versus Democratic Societies. Working Paper no 10037, NBER, Cambridge, Mass.

Acemoglu, D. and S. Johnson. 2005. Unbundling Institutions. The Journal of Political Economy 113(5): 949-95.

Acemoglu, D. and J. Robinson. 2000. Democratization or repression? European Economic Review 44(4-6): 683-93.

- 2000a. Political Losers as a Barrier to Economic Development. American Economic Review 90(2): 126-30.

_ 2000b. Why Did the West Extend the Franchise? Democracy, Inequality and Growth in Historical Perspective. Quarterly Journal of Economics 115(4): 1167-99.

938-63.

. 2001. A Theory of Political Transitions. American Economic Review 91(4):

2006a. De Facto Political Power and Institutional Persistence. American Economic Review 96(2): 325-30.

- 2006b. Persistence of Power, Elites and Institutions. Working Paper no 12108, NBER, Cambridge, Mass.

Acemoglu, D. and T. Verdier. 1998. Property Rights, Corruption and the Allocation of Talent: A General Equilibrium Approach. The Economic Journal 108(450): 1381-403.

Acemoglu, D., S. Johnson, and J. Robinson. 2001. Colonial Origins of Comparative Development: an Empirical Investigation. American Economic Review 91(5): 1369-401.

- 2002. Reversal of Fortune: Geography and Institutions in the Making of the Modern World Income Distribution. Quarterly Journal of Economics 117(4): 1231-94. 
- 2004. Institutions as the Fundamental Cause of Long-Run Growth. Prepared for the Handbook of Economic Growth edited by Aghion, P. and S. Durlauf.

- 2005. The Rise of Europe: Atlantic Trade, Institutional Change and Economic Growth. American Economic Review 95(3): 546-79.

- 2006. Economic Origins Of Dictatorship and Democracy: Economic and Political Origins. Cambridge, UK: Cambridge University Press.

Alesina, A. and D. Rodrik. 1994. Distributive Politics and Economic Growth. Quarterly Journal of Economics 109(2), 465-90.

Asoni, A. 2006. Colonial Heritage and Economic Development. Unpublished Manuscript, University of Chicago.

Baumol, W. J. 2002. The Free-Market Innovation Machine: Analyzing the Growth Miracle of Capitalism. Princeton, USA: Princeton University Press.

Bednar, J. and. S. E. Page. 2006a. Can Game(s) Theory Explain Culture? The Emergence of Cultural Behavior within Multiple Games. Working Paper no 04-12-039, SFI, Santa Fe, NM.

2006b. Culture, Institutional Performance, and Path Dependence. Working Paper no WP2006-6, Institute of Governmental Studies, University of California, Berkeley, CA.

Besley, Y. 1995. Property Rights and Investment Incentives: Theory and Evidence from Ghana. The Journal of Political Economy 103(5): 903-37.

Bourguignon, F. and T. Verdier. 2000. Oligarchy, democracy, inequality and growth. Journal of Development Economics 62(2): 285-313.

Chong, D. 2000. Rational Lives: Norms and Values in Politics and Society. Chicago: University of Chicago Press.

Chong, A. and C. Calderón. 2000. Causality and Feedback Between Institutional Measures and Economic Growth. Economics and Politics 12(1): 69-81

De Long, J. B. and A. Shleifer. 1993. Princes and Merchants: European City Growth before the Industrial Revolution. Journal of Law \& Economics 36(2): 671-702.

Cole, D. H. and P. Z. Grossman. 2002. The Meaning of Property Rights: Law versus Economics? Land Economics 78(3): 317-30.

De Soto, H. 1989. The Other Path: The Invisible Revolution in the Third World. New York: Harper. 

Group).

. 2000. The Mistery of Capital. New York, USA: Basic Books (Perseus Books

Diamond, J. 1997. Guns, Germs and Steel. New York, USA: W. W. Norton \& Co.

Dollar, D. and A. Kraay. 2004. Trade, Growth and Poverty. The Economic Journal 114(493): 22-49.

Galor, O., O. Moav, and D. Vollrath. 2006. Land Inequality and the Origin of Divergence and Overtaking in the Growth Process: Theory and Evidence. Brown University Economics Working Paper no. 06-14, Brown University, Providence, RI.

Greif, A. 1994. Cultural Beliefs and the Organization of Society: A Historical and Theoretical Reflection on Collectivist and Individualist Societies. The Journal of Political Economy 102(5): 912-50.

Greif A. and D. D. Laitin. 2004. A Theory of Endogenous Institutional Change. American Political Science Review 98(4): 633-52.

Grossman, H. I. and M. Kim. 1996. Inequality, Predation and Welfare. Working Paper no 5704, NBER, Cambridge, Mass.

Hall R. E and C. I. Jones. 1999. Why Do Some Countries Produce So Much More Output Per Worker Than Others? The Quarterly Journal of Economics 114(1): 83-116.

Huntington, S. P. 1981. American Politics: the Promise of Disharmony. Cambridge, MA: Belknap Press.

Jack, W. and R. Lagunoff. 2006. Dynamic Enfranchisement. Journal of Public Economics 90(4-5): 551-72.

Johnson, S., J. McMillan, and C. Woodruff. 2002. Property Rights and Finance. American Economic Review 92(5): 1335-56.

Juhn, C., K. M. Murphy, and B. Pierce. 1993. Wage Inequality and the Rise in Returns to skills. The Journal of Political Economy 101(3): 410-42.

Knack, S. and P. Keefer. 1995. Institutions and Economic Performance: Cross Country Tests Using Alternative Measures. Economics and Politics 7: 207-27.

Krusell, P. and J.-V. Rios-Rull. 1996. Vested Interests in a Theory of Stagnation and Growth. Review of Economic Studies 63(2): 301-329.

La Porta, R., F. Lopez-De-Silanes, A. Shleifer, and R. Vishny. 2002. Investor Protection and Corporate Valuation. Journal of Finance 57(3): 1147-70. 
Londregan, J. B. and K.T. Poole. 1990. Poverty, The Coup Trap, and the Seizure of Executive Power. World Politics 42(2): 151-83

Lucas, R. 1988. On the Mechanics of Economic Development. Journal of Monetary Economics 22(1): 3-22.

Mauro, P. 1995. Corruption and Growth. Quarterly Journal of Economics 110(3): 681-712.

Murphy, K. M., A. Shleifer, and R.W. Vishny. 1991. The allocation of Talent: Implications for Growth. Quarterly Journal of Economics 106(2): 503-30.

Review 83(2): 409-14

North, D. C. 1990. Institutions, institutional change and Economic Performance. Cambridge, UK: Cambridge University Press.

North, D. C. and R. P. Thomas. 1973. The Rise of the Western World. Cambridge, UK: Cambridge University Press.

North, D. C. and B. R., Weingast. 1989. Constitutions and Commitment: The Evolution of Institutional Governing Public Choice in Seventeenth-Century England. Journal of Economic History 49(4): 803-32.

Olson, M. 1982. The Rise and Decline of Nations: Economic Growth, Stagflation and Economic Rigidities. New Haven, USA, and London, UK: Yale University Press.

. 1991. Autocracy, Democracy and Prosperity. In Strategy and Choice edited by Zeckhauser, R., 131-57. Cambridge, USA: MIT Press. Science Review 87(3): 567-76.

Parente S. and E. C. Prescott. 1994. Barriers to Technological Adoption and Development. The Journal of Political Economy 102(2): 298-321. 89(5): 1216-33.

1999. Monopoly Rights as Barriers to Riches. American Economic Review

Persson, T. and G. Tabellini. 1994. Is Inequality Harmful for Growth? Theory and Evidence. American Economic Review 84(3): 600-621.

Przeworski, A. and F. Limongi. 1993. Political Regimes and Economic Growth. Journal of Economic Perspective 7(3): 51-69. 
Putnam, R. D. 1973. The Beliefs of Politicians: Ideology, Conflict, and Democracy in Britain and Italy. New Haven: Yale University Press.

Rodrik, D. 1999. Where Did All the Growth Go? External Shocks, Social Conflict, and Growth Collapses. Journal of Economic Growth 4(4): 385-412.

Rodrik, D., A. Subramanian, and F. Trebbi. Institutions Rule: The Primacy of Institutions over Geography and Integration in Economic Development. Journal of Economic Growth 9(2): 131-65.

Sachs, J. 2001. Tropical Underdevelopment. Working Paper no 8119, NBER, Cambridge, Mass.

Sachs, J. and A. Warner. 1995. Economic Reform and the process of Global Integration. Brookings Papers on Economic Activity 1: 1-118.

Solow, R. M. 1956. A Contribution to the Theory of Economic Growth. Quarterly Journal of Economics 70(1): 65-94.

Sonin, K. 2003. Why the rich may favor poor protection of property rights. Journal of Comparative Economics 31(4): 715-31.

Sokoloff, K. L. and S. L. Engerman. 2000. History Lessons: Institutions, Factors Endowments and Paths of Development in the New World. Journal of Economic Perspective 14(3): 217-32.

Svensson, J. 1998. Investment, Property Rights and Political Instability: Theory and Evidence. European Economic Review 42(7): 1317-1341. 